\title{
The Effect of Agility and Speed Training of Futsal Players Attending School of Physical Education and Sports on Aerobic Endurance
}

\section{Levent Tanyeri ${ }^{1}$ Sercan Öncen ${ }^{2}$}

Physical Education and Sports Department, Kafkas University, Kars, Turkey.

Emailivirynat1o@hotmail.com

"Physical Education and Sports Department, Tekirdă̆ Namık Kemal University, Tekirdağ, Turkey.

Email:soncen@nku.edu.tr

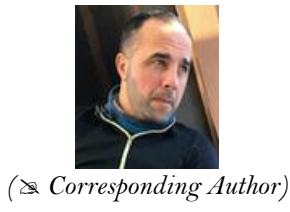

( Corresponding Author)

\section{Abstract}

Futsal is ateam game with hibg phsical demands players. Agility, aerobic and anaerobic power outputs of the players support the success in the game. 24 male players attending the Kafkas University having played futsal in the school team for at least one year participated in the study. The players were separated into two groups, The experimental group $(\mathrm{G} 1)$ performed sprints and circuits (agility training) of $10 \mathrm{~m}$ and $20 \mathrm{~m}$ integrated into a 30 minute training program after typical futsal training with their coach two days per week (Tuesdays and Thursdays) for six weeks. Additionally, on Thursdays, they participated in collective running at various paces, interval starts, and rank run exercises for aerobic endurance after typical futsal training. The control group (G2) performed their typical futsal training with their coach. The training sessions were planned so that there was at least a period of 36 hours between the two practice days. In order to determine the players' speed capacity, $10 \mathrm{~m}-20 \mathrm{~m}$ speed tests, a reactive agility tests, and aerobic endurance measurement yo-yo tests were implemented. Descriptive statistics were used in the data analysis, the Mann-Whitney U test was used in comparative analysis of the groups, and the significance was taken to be $p<0.05$. At the end of the study, it was revealed that the agility training of futsal players attending university for six weeks had an effect on their aerobic endurance.

Keywords: Futsal, Futsal player, Agility, Speed, Agility training, Speed training, Aerobic endurance.

Citation | Levent Tanyeri; Sercan Öncen (2020). The Effect of Agility and Speed Training of Futsal Players Attending School of Physical Education and Sports on Aerobic Endurance. Asian Journal of Education and Training, 6(2): 219-225.

History:

Received: 6 January 2020

Revised: 17 February 2020

Accepted: 20 March 2020

Published: 9 April 2020

Licensed: This work is licensed under a Creative Commons Attribution 3.0 License (cc) E

Publisher: Asian Online Journal Publishing Group
Acknowledgement: Both authors contributed to the conception and design of the study.

Funding: This study received no specific financial support

Competing Interests: The authors declare that they have no conflict of interests.

Transparency: The authors confirm that the manuscript is an honest, accurate, and transparent account of the study was reported; that no vital features of the study have been omitted; and that any discrepancies from the features of the study have been omittian
study as planned have been explained.

study as planned have been explained.
Ethical: This study follows all ethical practices during writing.

\section{Contents}

1. Introduction ......................220

2. Method..

3. Results...

References. 


\section{Contribution of this paper to the literature}

The effect of agility and speed training on aerobic endurance is resources that will help us better understand in futsal players.

\section{Introduction}

Futsal is a type of football played in a confined space and indoors. Since there are fewer players than in football and the playing field is narrower, futsal is a more dynamic and technique game. Actions such as take-off, sprints at different distances, deflections, an dribbling come to the forefront during futsal matches (Açak, Karademir, Taşmektepligil, \& Çalışkan, 2012). Thus, speed and agility are very important in futsal. Since play in futsal is very fast, unlimited player substitutions are allowed during matches and matches are limited to two periods of 20 minutes each (Katis \& Kellis, 2009).

Because futsal is a fast-moving game that includes many different movements, aerobic and anaerobic endurance is important (Alvurdu, Köse, \& Cinemre, 2016). Particularly, the intensive and maximal loading that exists in futsal causes aerobic endurance to be important. Thus, the effect of agility and speed training in the scope of aerobic endurance is significant. In this respect, the effect of agility and speed trainings on aerobic endurance on futsal on was emphasized in this study.

\subsection{The Structure of the Game in Futsal}

Futsal is field game played with five players on a side, goalkeepers included, in a field similar to a basketball court, structurally confined with specific lines. Although it is similar to football with respect to quality and gameplay, a futsal match is played at higher velocity than football because it is played within a more confined field. In addition, since the field is more confined, players are supposed to change their positions continuously as a whole team during defensive and offensive play (Barbero-Alvarez, Soto, Barbero-Alvarez, \& Granda-Vera, 2008; Moura et al., 2011). Players who have a higher technical capacity can be more successful in futsal because of confined space (Clemente, Couceiro, Martins, \& Mendes, 2012).

It has been observed that one of the important factors that increases the efficiency of the game is the amount of time that the players have to take action (Nicoletti \& Borghi, 2007). Players touch the ball a great deal in a limited time, which helps players improve their capacity for decision-making and technique. Additionally, since the game is dynamic and includes rapid transitions, players are more involved in the game. All these conditions necessitate a high level of aerobic and anaerobic performance, and, as evidenced by previous studies that have aerobic performance has a very significant role in determining the level of performance of the player (Mohr, Krustrup, \& Bangsbo, 2003; Weston, Castagna, Impellizzeri, Rampinini, \& Abt, 2007).

In futsal, each player needs to be very involved in the game because of the confined game space and limited number of players. In this respect, playing a game in a confined space necessitates creating more open space, running more, and being more active. Moreover, skill in playing one-to-one is required. Reducing space in defensive play, changing position rapidly, and completing actions that require agility are within the basic characteristics of this game (Katis \& Kellis, 2009; Ocak \& Buğdaycı, 2012).

With respect to futsal field size, the width is $15 \mathrm{~m}$ minimum and $25 \mathrm{~m}$. maximum; the length is $25 \mathrm{~m}$ minimum and $42 \mathrm{~m}$. maximum. These sizes change in international matches in which the width is $18 \mathrm{~m}$ minimum and $25 \mathrm{~m}$. maximum, and the length is $38 \mathrm{~m}$ minimum and $42 \mathrm{~m}$. maximum. The aforementioned sizes include the sidelines; the two short sidelines are called goal lines, and the two long sidelines are called throw-in lines. All lines are $8 \mathrm{~cm}$ wide. The diameter of the mid-court circle is $3 \mathrm{~m}$. The number of players is five on each team, goalkeeper included. A match may not start if there are fewer than three players on either team. The number of substitute players in international matches is a maximum of five, and there are no limitations on player substitutions during gameplay (Ocak \& Buğdayci, 2012). The futsal match consists of two periods of 20 minutes each. The duration of the game can be extended because of fouls and penalties (Sert, 2015)

\subsection{Speed and Agility}

Speed has been expressed as a player's quality of moving at high speed from one place to another, taking actions as fast as possible, and moving within the shortest period of time (Günay, Tamer, \& Cicioğlu, 2010). When speed is structurally and physiologically assessed, it expresses a motional ability depending on the functioning of the nervous and muscular system (Muratll, Kalyoncu, \& Şahin, 2007). According to another definition, speed expresses a physical value that begins with a stimulus directed to external resistance and occurs in a minority of instances in terms of completing a specific action and covering a specific distance. The speed ability of the object taking the action increases when the aforementioned value approaches zero (Dündar, 2003).

Speed is not a feature structurally connected to just one factor. Thus, factors such as technique and application cause a change in speed. This results in classifying speed in different forms (Karavelioğlu, 2008) like general and special speed as well as physiological speed and speed in terms of training. While general speed means that it does not belong to any particular classification and can refer to the speed of any movement, special speed means that movements that belong to a specific classification are performed at adequate speed (Bompa \& Buzzichelli, 2018). The types of physiological speed are perception speed, reaction speed, and action speed (acceleration speed, average speed, maximum speed) (Dündar, 2003; Unver, 2011). The types of speed in terms of training are the speed of the individual action, the frequency of the action, sprint speed, and speed durability (Baktaal, 2008; Dündar, 2003).

The concept of agility and the concept of speed are structurally intermingled. Agility expresses the ability to do the most work within a unit of time. The ability to reach the maximum speed of action and reaction and to change the direction or speed of all body movements as a response to a stimulus can be expressed as agility (Sönmez, 2014). 


\subsection{Aerobic Endurance}

Since the respiratory system has a particular capacity, when the necessity for oxygen reaches the highest level within the process, the amount of oxygen spent per minute remains the same even if the action increases. This quality, which differs between individuals, is expressed as maximal aerobic capacity. For individuals doing exercise, after a four-minute submaximal training, the pulse rate balances at around 160 beats $/ \mathrm{min}$. The level at which the amount of oxygen used is balanced is called the steady state; during exercise, this level is beside the point because a little oxygen difference occurs. However, it is possible to ameliorate this situation by taking breaks during training (Fox, Bowers, Foss, \& Mathews, 2011).

Aerobic endurance appears as a type of durability that comes out in scope of energy production of the organism. Especially for the exercises carried out without interruption for more than 10 minutes, aerobic endurance has been observed to be improved with the increased time. There is a balance between the work done and the energy spent within the scope of aerobic endurance. It is a type of endurance in which the organism does not experience an oxygen difference; in other words, the durability comes out in the environment with enough oxygen. In this type of durability, energy is produced from oxygen by using energy sources with oxidation (Weineck, 2011).

The aim of our study was to examine the effects that high intensity interval exercises and endurance exercises integrated into circuit training implemented for futsal players' produce in terms of speed, agility, and aerobic capacity.

\section{Method}

24 male players attending the Kafkas University Sarıkamış School of Physical Education and Sports and having played futsal on the school team for at least one year participated in the study. The players were separated into two groups. The experimental group (G1) participated in sprints and circuits (agility training) of $10 \mathrm{~m}$ and $20 \mathrm{~m}$ integrated into a 30 minutes training program after their typical futsal training with their coach two days a week (Tuesday and Thursday) for six weeks. Additionally, on Thursday they participated in collective running at various paces, interval starts, and stage run exercises for aerobic endurance after typical futsal training. The control group (G2) performed their typical futsal training with their coach. The training was planned so that there was a period of at least 36 hours between the two practice days. In order to determine the players' speed capacities, a $10 \mathrm{~m}-20 \mathrm{~m}$ speed test, a reactive agility test, and an aerobic endurance measurements Yo-Yo Test were implemented. Descriptive statistics were used in the data analysis, the Mann Whitney-U test was used in a comparative analysis of the groups, and the significance has been taken as $\mathrm{p}<0,05$.

\subsection{Experimental Exercise Program}

\subsubsection{Circuit Training Plan}

The circuit-training plan consisted of three high intensity sets implemented on Tuesdays during all six weeks. There were five-minute active resting periods between sets. Each bouts period was 30 sec. and included a 30 sec recovery period. Each bout included exercises such as sit-ups, half squats, double hands medicine ball throwing, bench press, rope jumping, reverse sit-ups, and box jumps.

The target heart rates of the research group were determined by the Karvonen method, and endurance exercises were carried out on Thursdays in the first, third, and fifth weeks.

\begin{tabular}{|c|c|c|c|c|c|}
\hline & Day & Exercise & Exercise Time & Exercise Intensity & Exercise Frequency \\
\hline \multirow[t]{2}{*}{ 1. Week } & Tuesday & $\begin{array}{l}\text { Circuit } \\
\text { Exercise }\end{array}$ & \multicolumn{3}{|c|}{$\begin{array}{l}\text { (30 sec Bouts x } 30 \text { sec Recovery) x } 3 \text { set } \\
\text { Sit-up, Half squat, Medicine ball douple hand throw, Bench press, Skipping, Back curl, Box } \\
\text { jump }\end{array}$} \\
\hline & Thursday & $\begin{array}{l}\text { Enduranc } \\
\text { e Exercise }\end{array}$ & $20 \mathrm{~min}$ & $\% 50$ & 1 day in a week \\
\hline \multirow[t]{2}{*}{ 2. Week } & Tuesday & $\begin{array}{l}\text { Circuit } \\
\text { Exercise }\end{array}$ & \multicolumn{3}{|c|}{$\begin{array}{l}\text { (30 sec Bouts x } 30 \text { sec Recovery) x } 3 \text { set } \\
\text { Sit-up, Half squat, Medicine ball douple hand throw, Bench press, Skipping, Back curl, Box } \\
\text { jump }\end{array}$} \\
\hline & Thursday & $\begin{array}{l}\text { İnterval } \\
\text { Exercise }\end{array}$ & $400 \mathrm{~m} \mathrm{x} 70 \mathrm{sec}$ & $\% 85-90$ & 1 day in a week \\
\hline \multirow[t]{2}{*}{ 3. Week } & Tuesday & $\begin{array}{l}\text { Circuit } \\
\text { Exercise }\end{array}$ & \multicolumn{3}{|c|}{$\begin{array}{l}\text { (30 sec Bouts x } 30 \text { sec Recovery) x } 3 \text { set } \\
\text { Sit-up, Half squat, Medicine ball douple hand throw, Bench press, Skipping, Back curl, Box } \\
\text { jump }\end{array}$} \\
\hline & Thursday & $\begin{array}{l}\text { Enduranc } \\
\text { e Exercise }\end{array}$ & $30 \mathrm{~min}$ & $\% 50$ & 1 day in a week \\
\hline \multirow[t]{2}{*}{ 4. Week } & Tuesday & $\begin{array}{l}\text { Circuit } \\
\text { Exercise }\end{array}$ & \multicolumn{3}{|c|}{$\begin{array}{l}\text { (30 sec Bouts x } 30 \text { sec Recovery) x } 3 \text { set } \\
\text { Sit-up, Half squat, Medicine ball douple hand throw, Bench press, Skipping, Back curl, Box } \\
\text { jump }\end{array}$} \\
\hline & Thursday & $\begin{array}{l}\text { İnterval } \\
\text { Exercise } \\
\end{array}$ & $650 \mathrm{~m} \mathrm{x} 140 \mathrm{sec}$ & $\% 80-85$ & 1 day in a week \\
\hline \multirow[t]{2}{*}{ 5. Week } & Tuesday & $\begin{array}{l}\text { Circuit } \\
\text { Exercise }\end{array}$ & \multicolumn{3}{|c|}{$\begin{array}{l}\text { (30 sec Bouts x } 30 \text { sec Recovery) x } 3 \text { set } \\
\text { Sit-up, Half squat, Medicine ball douple hand throw, Bench press, Skipping, Back curl, Box } \\
\text { jump }\end{array}$} \\
\hline & Thursday & $\begin{array}{l}\text { Enduranc } \\
\text { e Exercise }\end{array}$ & $30 \mathrm{~min}$ & $\% 60$ & 1 day in a week \\
\hline \multirow[t]{2}{*}{ 6. Week } & Tuesday & $\begin{array}{l}\text { Circuit } \\
\text { Exercise }\end{array}$ & \multicolumn{3}{|c|}{$\begin{array}{l}\text { (30 sec Bouts x } 30 \text { sec Recovery) x } 3 \text { set } \\
\text { Sit-up, Half squat, Medicine ball douple hand throw, Bench press, Skipping, Back curl, Box } \\
\text { jump }\end{array}$} \\
\hline & Thursday & $\begin{array}{l}\text { İnterval } \\
\text { Exercise }\end{array}$ & $900 \mathrm{~m} \times 200 \mathrm{sec}$ & $\% 75-80$ & 1 day in a week \\
\hline
\end{tabular}




\subsubsection{High Intensity Interval Exercise Plan}

A high intensity interval training program was carried out on Thursdays in the second, fourth, and sixth weeks. Interval exercises included races of $400 \mathrm{~m}, 650 \mathrm{~m}$ and $900 \mathrm{~m}$. Active recreation was implemented between loads until the heart rate decreased to 120-130 beats/min. An interval training program was carried out with one bouts in the first week and two bouts in the second and third weeks for the purpose of adapting the of members of the experimental group to the training. The participants who took part in the experimental training performed warm-up exercises for 5-10 minutes before the beginning of the exercise and cooling exercises for 5-10 minutes after the end of the training period.

\subsection{Experimental Study Measurement Tools \\ 2.2.1. Speed Measurements}

The $10 \mathrm{~m}$ and $20 \mathrm{~m}$ sprinting distances were measured by an electronic stopwatch (Microgate Witty) system with $0.01 \mathrm{sec}$. precision. The participants started a sprint at high speed from $50 \mathrm{~cm}$ behind the starting line. The best performance from both trials was recorded and taken under review.

\subsubsection{Agility measurements}

The agility of the participants was measured by a reactive agility test. In test, the participants moved to the first gate at maximum speed. Then, they changed direction and moved towards the second gate, and, after the second gate, they passed through the heightened gate in order to determine reactive agility. Measurements were carried out by Smart speed equipment, a system of reactive training testing.

\subsubsection{Anaerobic Endurance Measurements}

Yo-Yo intermittent recovery test one was implemented. The test was terminated when the person arrived at the point of exhaustion or if he missed the signal sound twice in a row (Bangsbo, Iaia, \& Krustrup, 2008).

\section{Results}

Table-2. Age, height, body weight and BMI values of the participants.

\begin{tabular}{c|c|c|c|c}
\hline Variable & Group & N & Average & Standard Deviation \\
\hline \multirow{2}{*}{ Age (years) } & Futsal (G1) & 12 & 20,75 & 2,25 \\
\cline { 2 - 5 } & Futsal (G2) & 12 & 21,25 & 2,15 \\
\hline \multirow{2}{*}{ Height $(\mathrm{cm})$} & Futsal (G1) & 12 & 173,20 & 5,92 \\
\cline { 2 - 5 } & Futsal (G2) & 12 & 174.40 & 5,25 \\
\hline \multirow{2}{*}{ Weight $(\mathrm{kg})$} & Futsal (G1) & 12 & 63,02 & 8,71 \\
\cline { 2 - 5 } & Futsal (G2) & 12 & 65,42 & 5,32 \\
\hline \multirow{2}{*}{ BMI } & Futsal (G1) & 12 & 21,04 & 2,87 \\
\cline { 2 - 5 } & Futsal (G2) & 12 & 21,46 & 2,43 \\
\hline
\end{tabular}

24 participations were included in the study. In Table 2 it was divided into two groups Futsal G1 n: 12 (age $20.75 \pm 2.25$ years; height $173.20 \pm 5.92 \mathrm{~cm}$; body weight $63.02 \pm 8.71 \mathrm{~kg}$; BMI $21.04 \pm 2.87)$ and Futsal G2 n: 12 (age $21.25 \pm 2.15$ years; height $174.4 \pm 5.25 \mathrm{~cm}$; body weight $65.42 \pm 5.32 \mathrm{~kg}$; BMI $21.46 \pm 2.43$ ).

\subsection{Comparison of Pre-test and Post-test of Futsal Experimental Group} study.

Comparison of Pre-test and Post-test of Futsal experimental group has been carried out at this stage of the

Table-3. Comparison of pre-test and post-test of anthropometric measurements of futsal experimental group.

\begin{tabular}{c|c|c|c|c|c}
\hline Variable & Tests & Average & Standard Deviation & $\mathbf{Z}$ & $\mathbf{p}$ \\
\hline \multirow{2}{*}{ Height $(\mathrm{cm})$} & Pre test & 173,20 & 5,926 & \multirow{2}{*}{0,687} & \multirow{2}{*}{0,104} \\
\cline { 2 - 5 } & Post test & 173,50 & 5,939 & & \multirow{2}{*}{0,000} \\
\hline \multirow{2}{*}{ Weight $(\mathrm{kg})$} & Pre test & 63,02 & 8,718 & \multirow{2}{*}{0,000} \\
\cline { 2 - 4 } & Post test & 62,39 & 8,516 & & \\
\hline
\end{tabular}

The results (in Table 3) of the pre-test and post-test of the anthropometric measurements of the experimental group were compared. According to the test results, there was a difference between the pretest and post-test in weight measurements $(\mathrm{p}<0.05)$. The post-test data in weight measurements $(63.39 \pm 8.516)$ were lower than the pre-test data $(63.02 \pm 8.718)$.

\begin{tabular}{c|c|c|c|c|c}
\multicolumn{2}{c}{ Table-4. Comparison of pre-test and post-test of speed measurements of futsal experimental group. } \\
\hline Variable & Tests & Average & Standard Deviation & $\mathbf{Z}$ & $\mathbf{p}$ \\
\hline \multirow{2}{*}{ 10m Speed Test (sec) } & Pre test & 1,75 & 0,084 & \multirow{2}{*}{3,245} & \multirow{2}{*}{0,000} \\
\cline { 2 - 5 } & Post test & 1,69 & 0,085 & \multirow{2}{*}{3,489} & \multirow{2}{*}{0,000} \\
\hline \multirow{2}{*}{ 20m Speed Test (sec) } & Pre test & 3,46 & 0,164 & 0,162 & \\
\cline { 2 - 4 } & Post test & 3,39 & & \\
\hline
\end{tabular}

In Table 4 the results of the pre-test and post-test speed measurements of the experimental group were compared. According to the results of the test, there was a difference between the pretest and post-test in the $10 \mathrm{~m}$ speed test and the $20 \mathrm{~m}$ speed test measurements $(\mathrm{p}<0.05)$. In the $10 \mathrm{~m}$ speed measurements, the post-test data 
$(1.69 \pm 0.085)$ was more favorable than the pre-test data $(1.75 \pm 0.084)$. In the $20 \mathrm{~m}$ speed measurements, the posttest data (3.39 \pm 0.162$)$ was more favorable than the pre-test data $(3.46 \pm 0.164)$.

Table-5. Comparison of pre-test and post-test of agility measurements of futsal experimental group.

\begin{tabular}{c|c|c|c|c|c}
\hline Variable & Tests & Average & Standard Deviation & $\mathbf{Z}$ & $\mathbf{p}$ \\
\hline \multirow{2}{*}{ Right } & Pre test & 4.01 & 0,100 & \multirow{2}{*}{3,699} & \multirow{2}{*}{0,000} \\
\cline { 2 - 5 } & Post test & 3,85 & 0,145 & \multirow{2}{*}{0,671} & \multirow{2}{*}{0,000} \\
\hline \multirow{2}{*}{ Left } & Pre test & 4,05 & 0,098 & 0,121 & \\
\cline { 2 - 5 } & Post test & 3,87 & & & \\
\hline
\end{tabular}

In Table 5 the results of the pre-test and the post-test of for agility in the experimental group were compared. According to the results, there was a difference between the pre-test and post-test in the right and left measurements $(\mathrm{p}<0.05)$. In the right measurements, the post-test data $(3.85 \pm 0.145)$ was more favorable than the pre-test data $(4.01 \pm 0.100)$. In the left measurements, the post-test data $(3.87 \pm 0.121)$ was more favorable than the pre-test data $(4.05 \pm 0.098)$.

\begin{tabular}{c|c|c|c|c|c}
\multicolumn{2}{c}{ Table-6. Comparison of pre-test and post-test of aerobic endurance measurements of futsal experimental group. } \\
\hline Variable & Tests & Average & Standard Deviation & $\mathbf{Z}$ & $\mathbf{p}$ \\
\hline \multirow{2}{*}{ YO-YO } & Pre test & 1098,95 & 120,273 & \multirow{2}{*}{3,847} & \multirow{2}{*}{0,000} \\
\cline { 2 - 5 } & Post test & 1178,00 & 124,292 & \\
\hline
\end{tabular}

The results of the pre-test and post-test for endurance in the experimental group were compared (Table 6). According to the results of the test, there was a difference between the pre-test and post-test in the yo-yo measurements $(\mathrm{p}<0.05)$. In the yo-yo measurements, the post-test data $(1178.00 \pm 124.292)$ were more favorable than the pre-test data $(1098.95 \pm 120.273)$.

\subsection{Comparison of Pre-test and Post-test of Futsal Control Group has been Carried Out at This Stage of the} Study.

Table-7. Comparison of pre-test and post-test of anthropometric measurements of futsal control group.

\begin{tabular}{c|c|c|c|c|c}
\hline Variable & Tests & Average & Standard Deviation & $\mathbf{Z}$ & $\mathbf{p}$ \\
\hline \multirow{2}{*}{ Height $(\mathrm{cm})$} & Pre test & 175,45 & 5,781 & \multirow{2}{*}{1,651} & \multirow{2}{*}{0,112} \\
\cline { 2 - 5 } & Post test & 176,00 & 5,912 & \multirow{2}{*}{0,000} \\
\hline \multirow{2}{*}{ Weight $(\mathrm{kg})$} & Pre test & 64,34 & 6,169 & \multirow{2}{*}{0,000} \\
\cline { 2 - 4 } & Post test & 63,70 & 6,143 & & \\
\hline
\end{tabular}

The results of the pre-test and post-test for the anthropometric measurements of the control group were compared (Table 7). According to the test results, there was a difference between the pre-test and the post-test for weight measurements $(\mathrm{p}<0.05)$. The weight measurements in the post-test data $(63,70 \pm 6,143)$ were lower than in the pre-test data $(63.34 \pm 6.169)$.

Table-8. Comparison of pre-test and post-test of speed measurements of futsal control group.

\begin{tabular}{|c|c|c|c|c|c|}
\hline Variable & Tests & Average & Standard Deviation & $\mathbf{Z}$ & p \\
\hline \multirow{2}{*}{ 10m Speed Test (sec) } & Pre test & 1,74 & 0,060 & \multirow{2}{*}{2,421} & \multirow{2}{*}{0,015} \\
\hline & Post test & 1,73 & 0,064 & & \\
\hline \multirow{2}{*}{ 20m Speed Test (sec) } & Pre test & 3,47 & 0,135 & \multirow{2}{*}{3,205} & \multirow{2}{*}{0,001} \\
\hline & Post test & 3,44 & 0,139 & & \\
\hline
\end{tabular}

The results of the pre-test and the post-test speed measurements of the control group were compared (Table 8). According to the results, there was a difference between the pre-test and the post-test in the $10 \mathrm{~m}$ speed test and the $20 \mathrm{~m}$ speed test $(\mathrm{p}<0.05)$. In the $10 \mathrm{~m}$ speed measurements, the post-test data $(1.73 \pm 0.064)$ were more favorable than the pre-test data $(1.74 \pm 0.060)$. In the $20 \mathrm{~m}$ speed measurements, the post-test data $(3.44 \pm 0.139)$ were more favorable than the pre-test data $(3.47 \pm 0.135)$.

Table-9. Comparison of pre-test and post-test of agility measurements of futsal control group.

\begin{tabular}{|c|c|c|c|c|c|}
\hline Variable & Tests & Average & Standard Deviation & $\mathbf{Z}$ & p \\
\hline \multirow{2}{*}{ Right } & Pre test & 3,96 & 0,112 & \multirow{2}{*}{2,768} & \multirow{2}{*}{0,006} \\
\hline & Post test & 3,93 & 0,103 & & \\
\hline \multirow{2}{*}{ Left } & Pre test & 4,02 & 0,115 & \multirow{2}{*}{2,076} & \multirow{2}{*}{0,038} \\
\hline & Post test & 3,99 & 0,138 & & \\
\hline
\end{tabular}

The results of the pre-test and the post-test for agility for the control group were compared (Table 9). According to the results of the tests, there was a difference between the pre-test and the post-test in the right and left measurements $(\mathrm{p}<0.05)$. In right measurements, the post-test data $(3.93 \pm 0.103)$ was more favorable than the pre-test data $(3.96 \pm 0.112)$. In the left measurements, the post-test data $(3.99 \pm 0.138)$ were more favorable than the pre-test data $(4.02 \pm 0.115)$.

Table-10. Comparison of pre-test and post-test of aerobic endurance measurements of futsal control group.

\begin{tabular}{l|c|c|c|c|c}
\hline Variable & Tests & Average & Standard Deviation & $\mathbf{Z}$ & $\mathbf{p}$ \\
\hline \multirow{2}{*}{ YO-YO } & Pre test & 1127,00 & 82,660 & \multirow{2}{*}{3,070} & \multirow{2}{*}{0,002} \\
\cline { 2 - 4 } & Post test & 1164,00 & 80,420 & \\
\hline
\end{tabular}


In Table 10 the results of the pre-test and the post-test for endurance in the control group were compared. According to the results, there was a difference between the pre-test and post-test in the yo-yo measurements $(\mathrm{p}<0.05)$. In the yo-yo measurements, the post-test data $(1164.00 \pm 80.420)$ was more favorable than the pre-test data $(1127.00 \pm 82.660)$.

\subsection{Comparison of Pre-test and Post-test of Futsal Experimental and Control Group}

Table-11. Comparison of pre-test and post-test of anthropometric measurements of experimental and control group.

\begin{tabular}{|c|c|c|c|c|c|c|}
\hline Variable & Tests & Group & Average & Standard Deviation & $\mathbf{Z}$ & p \\
\hline \multirow{4}{*}{ Height $(\mathrm{cm})$} & \multirow{2}{*}{ Pre-test } & Futsal (G1) & 173,20 & 5,926 & \multirow{2}{*}{1,342} & \multirow{2}{*}{0,183} \\
\hline & & Futsal (G2) & 175,45 & 5,781 & & \\
\hline & \multirow{2}{*}{ Post-test } & Futsal (G1) & 173,70 & 5,939 & \multirow{2}{*}{1,372} & \multirow{2}{*}{0,170} \\
\hline & & Futsal (G2) & $176, \mathrm{OO}$ & 5,912 & & \\
\hline \multirow{4}{*}{ Weight (kg) } & \multirow{2}{*}{ Pre-test } & Futsal (G1) & 63,02 & 8,718 & \multirow{2}{*}{1,177} & \multirow{2}{*}{0,242} \\
\hline & & Futsal (G2) & 64,34 & 6,169 & & \\
\hline & \multirow{2}{*}{ Post-test } & Futsal (G1) & 62,39 & 8,516 & \multirow{2}{*}{1,150} & \multirow{2}{*}{0,253} \\
\hline & & Futsal (G2) & 63,70 & 6,143 & & \\
\hline
\end{tabular}

At this stage of the study, a comparison of the pre-tests and the post-tests for the experimental and control group was conducted. In terms of the anthropometric measurements of the experimental and the control groups, there was no difference between the pre-tests and post-tests for the height and weight measurements (Table 11$)$.

\begin{tabular}{|c|c|c|c|c|c|c|}
\hline Variable & Tests & Group & Average & Standard Deviation & $\mathbf{Z}$ & p \\
\hline \multirow{4}{*}{ 10m Speed Test (sec) } & \multirow{2}{*}{ Pre-test } & Futsal (G1) & 1,75 & 0,084 & \multirow{2}{*}{0,421} & \multirow{2}{*}{0,674} \\
\hline & & Futsal (G2) & 1,74 & 0,060 & & \\
\hline & \multirow{2}{*}{ Post-test } & Futsal (G1) & 1,69 & 0,085 & \multirow{2}{*}{4,521} & \multirow{2}{*}{0,000} \\
\hline & & Futsal (G2) & 1,73 & 0,064 & & \\
\hline \multirow{4}{*}{ 20m Speed Test (sec) } & \multirow{2}{*}{ Pre-test } & Futsal (G1) & 3,46 & 0,164 & \multirow{2}{*}{0,122} & \multirow{2}{*}{0,903} \\
\hline & & Futsal (G2) & 3,47 & 0,135 & & \\
\hline & \multirow{2}{*}{ Post-test } & Futsal (G1) & 3,39 & 0,162 & \multirow{2}{*}{3,694} & \multirow{2}{*}{0,000} \\
\hline & & Futsal (G2) & 3,44 & 0,139 & & \\
\hline
\end{tabular}

In terms of the speed measurements between the pre-tests and post-tests for the experimental and control groups, it was determined that there was a significand difference. While there was no difference between the experimental group and the control group in terms of the pre-test results for the $10 \mathrm{~m}$ speed test $(\mathrm{p}>0,05)$, there was a difference in the post-test results $(\mathrm{p}<0.05)$. The $10 \mathrm{~m}$ speed measurements of the experimental group $(1.69 \pm$ $0.085)$ developed more positively than the control group $(1.73 \pm 0.064)$. While there was no difference between the experimental group and the control group in terms of the pre-test results for the $20 \mathrm{~m}$ speed test $(\mathrm{p}>0.05)$, there was a difference in the post-test results $(\mathrm{p}<0.05)$. The $20 \mathrm{~m}$ speed measurements for the experimental group (3.39 $\pm 0.162)$ developed more positively than the control group (3.44 \pm 0.139$)$.

Table-13. Comparison of pre-test and post-test of agility measurements of experimental and control group.

\begin{tabular}{|c|c|c|c|c|c|c|}
\hline Variable & Tests & Group & Average & Standard Deviation & $\mathbf{Z}$ & p \\
\hline \multirow{4}{*}{ Right } & \multirow{2}{*}{ Pre test } & Futsal (G1) & 4,01 & 0,100 & \multirow{2}{*}{1,341} & \multirow{2}{*}{0,180} \\
\hline & & Futsal (G2) & 3,96 & 0,112 & & \\
\hline & \multirow{2}{*}{ Post test } & Futsal (G1) & 3,85 & 0,145 & \multirow{2}{*}{3,842} & \multirow{2}{*}{0,000} \\
\hline & & Futsal (G2) & 3,93 & 0,103 & & \\
\hline \multirow{4}{*}{ Left } & \multirow{2}{*}{ Pre test } & Futsal (G1) & 4,05 & 0,098 & \multirow{2}{*}{0,813} & \multirow{2}{*}{0,416} \\
\hline & & Futsal(G2) & 4,02 & 0,115 & & \\
\hline & \multirow{2}{*}{ Post test } & Futsal (G1) & 3,87 & 0,121 & \multirow{2}{*}{3,618} & \multirow{2}{*}{0,000} \\
\hline & & Futsal (G2) & 3,99 & 0,138 & & \\
\hline
\end{tabular}

When the results of the pre-test and post-test of agility measurements for the experimental and control group was compared (Table 13), it was found that while there was no difference between the experimental group and the control group in terms of the pre-test results of the right measurements $(p>0.05)$, there was a difference in the post-test results $(p<0.05)$. The right measurements for the experimental group $(3.85 \pm 0.145)$ developed more positively than the control group $(3.93 \pm 0.103)$. While there was no difference between the experimental group and control group in terms of the pre-test results for the left measurements $(p>0.05)$, there was a difference in the post-test results $(\mathrm{p}<0.05)$. The left measurements of the experimental group $(3.87 \pm 0.121)$ developed more positively than the control group (3.99 \pm 0.138$)$.

\begin{tabular}{|c|c|c|c|c|c|c|}
\hline Variable & Tests & Group & Average & Standard Deviation & $\mathbf{Z}$ & $\mathbf{p}$ \\
\hline \multirow{4}{*}{ YO-YO } & \multirow{2}{*}{ Pre-test } & Futsal (G1) & 1098,95 & 120,273 & \multirow{2}{*}{0,635} & \multirow{2}{*}{0,531} \\
\hline & & Futsal(G2) & 1127,00 & 82,660 & & \\
\hline & \multirow{2}{*}{ Post-test } & Futsal (G1) & 1188,00 & 124,292 & \multirow{2}{*}{3,481} & \multirow{2}{*}{0,000} \\
\hline & & Futsal (G2) & 1164,00 & 80,420 & & \\
\hline
\end{tabular}

When the results of pre-test and post-test for aerobic endurance measurements of experimental and control group were examined (Table 14), while there was no difference between the experimental group and the control group in terms of the pre-test results of the yo-yo measurements ( $>0,05)$, there was a difference in the post-test 
results $(\mathrm{p}<0.05)$. The yo-yo measurements of the experimental group $(1188.00 \pm 124.292)$ developed more positively than the control group (1164.00 \pm 80.420$)$.

\section{Conclusion}

Speed, agility, and endurance become recognized as important for players' high performance and success. An increase in the players' speed, agility, and endurance positively affects their performance. Training programs for players are significant in increasing the players' speed, agility, and endurance. Determining the appropriate training program is important for the development of players and for improving their skills. The effect of the futsal training programs on the players' speed, agility, and endurance was examined in this study. At the end of the study, it was concluded that the agility training of futsal players attending university for six weeks had an effect on aerobic endurance. Similarly, Balcığlu, 2018 implemented a six-week futsal training program for 12-14 year old boys in his study and pointed out that the agility skills of the children developed positively. Alvurdu, 2016 implemented an eight-week futsal training program for 16 futsal players on the team under 14. At the end of the study, it was determined that the agility skills of the players had developed positively. Since futsal is a game based on agility and speed and the players are involved in the game dynamically, futsal training programs have become important. Futsal players have to be speedy and durable and demonstrate high performance in harmony with the dynamic gameplay in order to be successful. For this reason, the effectiveness of the futsal training becomes significant.

This study was limited with 24 male players playing in the school futsal team and a six-week training program

\section{References}

Açak, M., Karademir, T., Taşmektepligil, Y., \& Çalışkan, E. (2012). Comparison of agility and visual reaction time of hearing-impaired futsal athletes. Selcuk University Journal of Physical Education and Sports Sciences, 14(2), 283-289.

Alvurdu, S., Köse, M. G., \& Cinemre, S. A. (2016). Evaluation of the relationship between anaerobic power and repetitive ability to change direction in futsal players. Gazi Journal of Physical Education and Sports Sciences, 21(1-4), 29-37.

Baktaal, D. G. (2008). The research about plyometrics training models on vertical jump in 16-22 age female volleyball players. Master Thesis University of Çukurova, Adana.

Bangsbo, J., Iaia, F. M., \& Krustrup, P. (2008). The Yo-Yo intermittent recovery test. Sports Medicine, 38(1), 37-51.Available at: https://doi.org/10.2165/00007256-200838010-00004.

Barbero-Alvarez, J., Soto, V., Barbero-Alvarez, V., \& Granda-Vera, J. (2008). Match analysis and heart rate of futsal players during competition. Journal of Sports Sciences, 26(1), 63-73.Available at: https://doi.org/10.1080/02640410701287289.

Bompa, T. O., \& Buzzichelli, C. (2018). Periodization-: Theory and methodology of training (pp. 114-144): Human Kinetics.

Clemente, F., Couceiro, M., Martins, F. M., \& Mendes, R. (2012). Team's performance on FIFA u17 world cup 2011 : Study based on notational analysis. Journal of Physical Education and Sport, 12(1), 13-17.

Dündar, U. (2003). Training theory. Ankara: Nobel Publishing.

Fox, E. L., Bowers, R. W., Foss, M. L., \& Mathews, D. K. (2011). The physiological basis of physical education, translation and compilation: Mesut CERIT. Ankara: Spor Publishing House and Bookstore.

Günay, M., Tamer, K., \& Cicioğlu, I. (2010). Sports physiology and performance measurement. Ankara: Gazi Bookstore.

Karavelioğlu, M. B. (2008). Comparing selected physical and motoric characteristics of Turkish amateur soccer players according to playing positions. Master Thesis University of Dumlupinar, Kütahya.

Katis, A., \& Kellis, E. (2009). Effects of small-sided games on physical conditioning and performance in young soccer players. Journal of Sports Science \& Medicine, 8(3), 374-380.

Mohr, M., Krustrup, P., \& Bangsbo, J. (2003). Match performance of high-standard soccer players with special reference to development of fatigue. Journal Sports Science, 21, 519-528.Available at: 10.1080/0264041031000071182.

Moura, F. A., Santana, J. E., Marche, A. L., Aguiar, T. H., Rodrigues, A. C. M., de Barros, R. M., \& Cunha, S. A. (2011). Quantıtatıve analysıs of futsal players organization on the court. Paper presented at the In ISBS-Conference Proceedings Archive.

Muratl, S., Kalyoncu, O., \& Şahin, G. (2007). Training and competition. Istanbul: Ladin Matbaacılık.

Nicoletti, R., \& Borghi, A. M. (2007). II controlomotorio. [Motor control. InItalian.]. Bologna: II Mulino.

Ocak, Y., \& Buğdaycı, S. (2012). Futsal. Istanbul: Bedray Publishing.

Sert, R. (2015). Investigation of some factors affecting percentage of shots in indoor soccer. Master Thesis University of Afyon Kocatepe, Afyon.

Sönmez, M. (2014). The effects of agzlity and sustained speed practice on performance in karate. Master Thesis University of Haliç, Health Sciences Institute, İstanbul.

Unver, R. (2011). Comparison of anaerobic power, force measurements and body composition parameters in elite young wrestlers. Master Thesis University of Kırıkkale, Kırıkkale.

Weineck, J. (2011). Condition training in football. (T. Bağirgan Trans.). Ankara: Sports Publishing and Book House.

Weston, M., Castagna, C., Impellizzeri, F. M., Rampinini, E., \& Abt, G. (2007). Analysis of physical match performance in English Premier League soccer referees with particular reference to first half and player workrates. Journal Science Med Sport, 10, 390-397.Available at: $10.1016 /$ j.jsams.2006.09.001. 